\title{
Textos y palabras. Cuatro documentos del siglo XVI
}

José LUIS MARTÍNEZ

\section{Los documentos}

Algunos de los documentos publicados en este volumen atraen la atención por sus coincidencias y elementos en común, lo que los transforma prácticamente en un conjunto documental que brinda la posibilidad de intentar una aproximación diferente a ellos, así como el obtener un tipo de información difícilmente alcanzable si se tratase de documentos no vinculados entre sí (AGI Patronato $188 \mathrm{n}^{\circ} 1$; Patronato $188 \mathrm{n}^{\circ}$ 4; Charcas 80; BNBA Col. GGV, doc. 1400). Todos se refieren a un mismo tema y época: las acciones emprendidas por algunos españoles en los territorios de Atacama y Tucumán, durante la segunda mitad del siglo XVI. Sus gestores y protagonistas son los mismos (o unos muy cercanos a ellos), tanto desde el lado español como -al menos aparentemente- desde el lado de los grupos indígenas involucrados. Ellos parecen presentar una poco usual perspectiva de descripción de los procesos de pacificación de los grupos indígenas de la región, poniéndose un claro énfasis en las estrategias políticas y negociadoras generadas por la familia de Juan Velázquez Altamirano con los dirigentes étnicos locales (chichas, atacamas, casavindos y de Humahuaca), por sobre las acciones de carácter militar también emprendidas por éste y otros capitanes españoles de la época. Es probablemente ese especial énfasis el que hace que los documentos contengan una información "etnográfica" que parece permitir una lectura que ponga al descubierto parte de la trama de las identidades y de las denominaciones de los grupos puneños, permitiendo de paso entrever sus territorialidades, así como sus relaciones mutuas y las tácticas generadas frente al avance colonial. En suma, permiten también visualizar una parte de los arreglos y tensiones a que en ese momento preciso -la segunda mitad del siglo XVI- se vieron sometidos los grupos que habitaban las tierras áridas del Altiplano Meridional, cuestión que fue abordada en un trabajo anterior (Martínez 1991).

Se trata así de un conjunto documental bastante cerrado, con un núcleo de información centrado en la pacificación de los atacamas y otros grupos vecinos, como casavindos y humaguacas, que proporciona una interesante perspectiva para el estudio de las poblaciones indígenas de la región.

\section{La heterogeneidad como estrategia}

Formalmente, estos documentos pertenecen a series diferentes. Se trata de una probanza de méritos, de una permuta de encomienda y de dos descripciones de pacificación, hechas aparentemente como antecedentes para la probanza de méritos. Sin embargo, mi propia aproximación anterior los "despoja" de ese carácter formal para transformarlos en informantes acerca de las sociedades indígenas, formulándoles un tipo de preguntas y problemas aparentemente desligados de su orientación inicial. Se trata, con todo, de una forma de abordaje de los documentos muy generalizada entre quienes se han abocado al estudio de las sociedades andinas, más particularmente aquellas de las tierras áridas de la Puna Salada y el Desierto de Atacama, pobres en crónicas y visitas.

Uno de los puntos de mayor consenso entre quienes estudian las poblaciones indígenas del Altiplano Meridional, en especial de las tierras que se extienden hacia el sur de la Audiencia de Charcas, es la escasez de material documental, ya sean crónicas, visitas o memoriales, que informen de una manera más detallada sobre estas poblaciones. La referencia a las dificultades generadas por la ausencia de textos -en especial los más tempranos- que entreguen antecedentes sobre esas poblaciones, sus estructuras sociales, políticas, económicas o religiosas es, prácticamente, un comentario obligado.

Frente a ello se ha ido generando una amplia gama de alternativas tácticas y estrategias de investigación, que buscan suplir de una $\mathrm{u}$ otra forma esos "vacíos" documentales (Lorandi 1977; Hidalgo 1978; Krapovickas 1978, 1983; Lorandi y Bunster 1987-88; Martínez et al. 1988; Martínez 1990; Schaposchnik 1991 Ms; entre otros). En particular si nos remitimos a los estudios sobre el siglo XVI, los análisis resultan 
generalmente de la reunión lenta y paciente de las fuentes más diversas. La estrategia de ir sumando pequeños datos aislados para pretender reconstruir fragmentos de un conjunto siempre esquivo, ha sido una práctica común y válida para todo este tipo de estudios. Así, estos análisis reúnen datos provenientes de fuentes parroquiales, de juicios y pleitos por encomiendas, censos y revisitas, cartas y relaciones, junto a todo otro documento que proporcione alguna información susceptible de ser utilizada.

En términos generales, la etnohistoria andina ha desarrollado formas propias de aproximación y de obtención de la información que puedan proporcionar ciertos tipos de documentos y textos, tales como las crónicas, visitas y memoriales (Araníbar 1963; Wedin 1966; Zuidema 1973, 1977, 1990; Murra 1975, 1989; Pease Ms, 1978a y b; Saignes 1980, 1986, Urton 1989, entre otros). El punto central de este desarrollo ha sido, me parece, su valoración como restos de lo que alguna vez fue voz hablada, fue relato oral e información recogida o entregada directamente por un informante andino. A pesar de los aportes arqueológicos o de otras disciplinas que ciertamente enriquecen y amplían el horizonte de la etnohistoria ${ }^{1}$, son precisamente los documentos escritos los que constituyen la base del quehacer etnohistórico, en virtud de esa relación especial entre oralidad y testimonialidad que se les asigna como partida de nacimiento. $\mathrm{Y}$ ha sido precisamente la búsqueda de textos que expresen con mayor nitidez y fuerza la palabra (y la práctica) andina, la que ha llevado a la utilización de fuentes tales como las visitas y memoriales, hasta entonces prácticamente desconocidos para los trabajos históricos.

El problema que se presenta para los estudios etnohistóricos más regionales, como los que aquí enfrentamos sobre las poblaciones de la Puna Salada y las tierras áridas al sur de la Audiencia de Charcas, es que los documentos y textos que son usados como fuentes provienen de series documentales diferentes, la gran mayoría de ellas con un tangencial o escaso interés por la información directa sobre lo indígena. A diferencia de las series documentales como visitas o, aun, pleitos por curacazgos, en éstos las voces indígenas están ausentes. Aquí se expresa -con claridad- una mirada, la europea, sobre un sector

1 No podría dejar de nombrar aquí a John Murra, que tantos esfuerzos y años ha dedicado a la tarea de unir, en un proyecto más común, a los arqueólogos del Período Tardío andino y a los etnohistoriadores. del espacio andino y sobre las relaciones que esa mirada es capaz de percibir y decodificar. Se trata, en suma, de documentos para los cuales la etnohistoria no ha generado una reflexión similar a la referente a crónicas o visitas y que plantean una relación particular con respecto a la palabra indígena.

Esta práctica común de rescate y suma de datos aislados, obtenidos de una amplia gama de tipos documentales -de la que es expresión también el volumen en el cual va este trabajo- no deja de plantearme varios problemas. Por varias razones. En primer lugar, se trata generalmente de una lectura entre líneas de las pequeñas frases que adquieren sentido únicamente en el seno de un todo mayor (nuestro propio relato) y que supone, por lo tanto, que hay una discursividad común a todos los documentos utilizados como fuente, que hace válida la práctica de extraer fragmentos para unirlos en un nuevo orden, dispuesto esta vez por el etnohistoriador. Que todos esos papeles, en alguna medida, describen una misma "realidad" y lo hacen bajo los mismos parámetros. En segundo lugar, por lo general las condiciones de producción del texto no son cuestionadas. No me refiero a si se trata de datos verídicos o falsos, moderados o exagerados, ni al típico análisis heurístico historiográfico, sino al tipo de relato del cual provienen: ¿qué "realidad" reflejan, si es que lo hacen?, ¿qué aspectos son excluidos de cada texto de acuerdo a su discursividad específica?, ¿pueden estos datos ser usados libremente, al margen del tipo de documentos del cual se extraigan?, ¿qué ocurre con las series a las cuales pertenecen los textos utilizados y sus respectivos sistemas discursivos?

Parte del problema viene también, me parece, de un tipo de aproximación al documento, que ha sido característico de la etnohistoria andina y que pretende "traspasar" el documento para obtener, en una pesquisa etnográfica, la voz ausente, la oralidad perdida de los hombres andinos (Wachtel 1976; Rostworowski 1977, 1981, 1988; Pease 1991a y b). Esta aproximación conlleva -de una u otra manerauna suerte de disolución del documento, que lo minimiza como tal, en busca del "verdadero" orden que estaría detrás (o más allá) de él. "Se trata, en cierto modo, de pasar al otro lado del escenario y escrutar la historia al revés", señalaba Wachtel (1976: 24), lo que, en el caso de ciertos documentos, termina por implicar la ausencia de un análisis sobre los textos en sí, no como origen de la información, sino como formas concretas y determinadas de 
organizar un relato específico, de describir, bajo formas pautadas también culturalmente, la dinámica de las sociedades andinas.

Así como buscamos y encontramos regularidades en el discurso andino rescatado, como trabajamos con etnocategorías lingüísticas andinas que son expresión de una determinada cosmovisión y que, por lo tanto, organizan de una u otra forma la producción oral andina, debiera ser factible hacerlo igualmente con los textos hispanos. Todos estamos ya familiarizados con los efectos discursivos que implica el uso -en las crónicas y otros documentos- de los conceptos europeos de tiempo y espacio, tan diferentes a los andinos (Hardmann 1988), o del manejo de categorías tales como "monarquía", "rey", etc. Pero se trata de una labor aún inconclusa.

Continuarla, esta vez con materiales diferentes y sobre épocas y temas distintos, parece ser un paso necesario para poder aclarar la existencia de ese "orden del discurso" que, más allá de lo formal del documento y de sus características, refleje esas formas comunes de pensamiento que se ha asumido se encontrarían allí y que posibilitan, por lo tanto, nuestros análisis "heterogéneos". Con esto no quiero plantear aquí que esta práctica a la cual me he referido no se haga, sino la necesidad de enfatizar una reflexión más profunda sobre ella, sus supuestos y sus resultados.

Por sus características temáticas comunes, que cruzan sus diferentes tipologías formales, me parece que los documentos reunidos aquí podrían proporcionar la posibilidad de intentar una aproximación a algunos de estos problemas, en especial a la existencia o inexistencia de ciertos procedimientos descriptivos que podrían implicar, por un lado, el empleo de términos más o menos generalizados y pautados, usados para referirse a los grupos indígenas y, por otro lado, el que esos mismos procedimientos generen una descripción que impone sus propios puntos de referencia, excluyendo el relato de otros elementos o aspectos.

Una primera aproximación parece posible a partir del enunciado. Me he permitido tomar este término de la lingüística en tanto se entiende como toda entidad provista de sentido y que es posible destacar de una cadena hablada o de un texto escrito, independientemente de sus dimensiones sintácticas (frase o discurso), antes de efectuar un análisis lingüístico (Greimas y Courtés 1979: 123).
En virtud de los intereses específicos de una metodología etnohistórica, he privilegiado aquellos enunciados que parecieran tener un sentido que pudiera estar vinculado a la descripción sobre los grupos indígenas. De los varios enunciados posibles de encontrar en este conjunto documental, he escogido uno: Por ser la tierra reuelada y los yndios alçados, que me pareció satisfacía varias de las condiciones impuestas por la necesidad de nuestro análisis. En primer lugar, se encuentra -prácticamente sin modificaciones- en el conjunto de los documentos; en segundo lugar, parece ocupar una posición nuclear al interior de cada relato y, por último, porque también ha constituido la base o el trasfondo explicativo (tanto procesual como factual) de muchos de los análisis históricos y etnohistóricos efectuados sobre la región. Se trata, así, de un enunciado que cumple con el doble desempeño de articular el relato documental y el discurso etnohistórico.

Primero procederemos a establecerlo como enunciado, a precisar algunas de sus condiciones de existencia y enunciación y posteriormente procuraré desmontarlo en algunas unidades menores.

\section{"Por ser la tierra reuelada y los yndios alçados"}

Esta frase me llamó siempre la atención, en parte por su riqueza expresiva y en parte porque, de una u otra forma, parece sintetizar uno de los núcleos que articulan la textualidad de las probanzas de méritos de la familia Velázquez Altamirano (AGI Charcas 80). Esto de por sí ya me resulta sugerente, pues se trata de tres probanzas que fueron reunidas en un mismo documento en virtud de su tramitación burocrática y no de su vecindad cronológica, ya que entre ellas hay al menos 30 años de diferencia. A pesar de ese lapso de tiempo y de que enfatizan la narración de procesos diferentes (las pacificaciones de Atacama y Humahuaca), hay evidentes lazos de continuidad discursiva entre unas y otras.

El enunciado "la tierra rebelada y los indios alzados", que se reitera, con leves variaciones, sistemáticamente a lo largo de todo el documento, parece jugar aquí al menos una doble función: por una parte, constituye uno de los aparentes sustentos de la justificación de los "méritos y servicios" (la rebelión indígena obliga a los hechos de la pacificación); por otra, parece sostener el armazón "anecdótico" del relato, al articular y explicar (o dar sentido) a las acciones realizadas. 
"El camino de aqui [Charcas] a Tucuman a estado los años passados muy peligrosso e los yndios de guerra y algados e que no se podia passar ni estar en la dicha prouinçia sin fuerza de gente y armas de lo qual resultaban muertes y robos..." (AGI Charcas 80 , f. 26v.).

“... en lo qual el dicho don Françisco Altamirano por ser la tierra reuelada y los yndios alçados se pospusso [sic] a mucho trauajo riesgo e peligro de la uida y mediante la yndustria cuydado e diligencia que el dicho don Françisco Altamirano pusso traxo de paz a don Diego Viltipoco y a sus yndios y a los de omaguaca que era capitan de toda aquella prouinçia que estauan aleados y reuelados..." (AGI Charcas 80, f. 30r.).

“... los yndios de Atacama a la sazon que la pregunta dize estauan alçados y de guerra e como tales matauan muchos españoles que passauan por su tierra como fue a la gente que entrauan en las prouincias de Chile y Tucuman con Joan Nuñez de Prado y otros capitanes..." (AGI Charcas 80, f. 67r.).

Lo interesante es que se trata de un enunciado presente también en otros textos contemporáneos, al interior de los cuales pareciera ocupar una posición similar a la señalada. En otra probanza de méritos, esta vez de los herederos de Martín Monje, encomendero de Humahuaca, se señala:

“... y el dicho presidente liçençiado Gasea vistos los seruiçios del dicho capitan Martin Monxe le dio en nombre de su magestad los repartimientos de Casauindo y Cosinoca porque hera fama que he-ran los mejores que en aquella saçon auia la qual dicha merced salio ynçierta porque ha mas de çinquenta años que están los dichos yndios alçados e de guerra..." (AGI Patronato 137 doc. 1 ramo 11).

Muchos de los documentos relativos a la región de la Puna Salada y las tierras áridas adyacentes, durante la segunda mitad del siglo XVI, contienen expresiones como ésta. Una suerte de "caracterización regional" que pareciera operar, de una u otra forma, como un marco global o un trasfondo de documentos muy disímiles. No sólo de los que citamos aquí, sino también de otros. Ya sea para describir las actuaciones de algunos españoles o para minimizarlas; para relatar la penetración hispana a esos territorios; para describir las características de sus gobiernos o dar explicaciones sobre determinados actos de éstos, la percepción sobre "la tierra rebelada y los indios alzados y de guerra" se generaliza, haciendo de este aspecto un elemento en común de un discurso más colectivo, que pareciera cruzar una parte importante de la documentación de la época, independientemente de los tipos documentales y que, junto con servir de excusa o justificación, pareciera generar una suerte de representación, casi un enunciado descriptivo que permite englobar múltiples situaciones, grupos y acontecimientos, junto con ordenar, de alguna manera, un discurso sobre ellos.

Frases similares se repiten en otros documentos ${ }^{2}, \mathrm{o}$ en contrario, para demostrar que se trata de situaciones superadas:

"A la sesta pregunta dixo este testigo que saue por cosa çierta questos indios son paçificos y que al dia de oi lo están mui mucho i questo lo saue porque a estado entrellos i uiuido entrellos de mas de beinte años a esta parte i que decir que son belicosos i de guerra ques falsedad i mentira..." (ANB C. 1591. VII. 19 nº 417, f. 2v, en Martínez 1985: 168).

Preguntas y respuestas que dialogan con otras preguntas y respuestas de otros discursos, de otros textos y documentos. El decir "falso y mentiroso" que se niega está en otro u otros documentos. $\mathrm{La}$ intertextualidad, el diálogo entre documentos parece muy fuerte. Se trata de una relación que nuevamente exhibe un doble carácter. Por una parte, todas estas referencias parecen remitirse a una cierta discursividad social, de manera tal que la sola mención "indios de guerra" pudiera estar invocando un conjunto mayor de atributos que no es necesario explicitar y que para un contemporáneo podrían tener un sentido y, simultáneamente, se trata de una forma escrita, ya codificada, textual y ya no oral.

La "tierra", como "conjunto de habitantes", parece englobar variados grupos, dispersos en una amplia y a veces difusa geografía. Los que están rebelados son "los yndios de Omaguaca Casauindo y Calchaqui", pero también los atacamas "aveis andado alzado y traido con vos y en vuestra compañía algunos caciques e yndios vuestros comarcanos", "Toda la qual dicha probinçia hasta la hecha [sic] desta sienpre han estado rebelados" (los de Casabindo). Se trata de grupos "poblados en tierra de guerra". Los atacamas, aun

2 AGI Patronato $188 \mathrm{n}^{\circ} 1 \mathrm{f}$. 1v; AGI Patronato $188 \mathrm{n}^{\circ} 4 \mathrm{f}$. 2 r; BNBA doc. 1400; BNBA doc. 1481; BNBA doc. 1234, p. 2 y ss. 
después de su pacificación, siguen siendo "yndios mesclados con los de guerra". Los "yndios omaguacas apatamas casauindos y calchaquies" causaban muchos estragos, junto a otros "circunvezinos" o "comarcanos", así como los de "Cochinoca e otros muchos en la provincia de Tucuman y camino della", a los que se puede agregar los de Ocloya, los del valle de Jujuy, etc. ${ }^{3}$

Como efecto discursivo, me parece que este tipo de descripción genera, en una primera instancia, una mirada homogeneizadora que oculta cualquier percepción de matices o diferencias entre esos grupos, así como proporciona una imagen de dispersión territorial sobre la cual volveremos más adelante.

Es precisamente con este argumento de una tierra rebelada y de guerra que -en un documento completamente diferente a los que hemos visto y con distinto destinatario- el virrey Toledo justifica la no realización de la Visita a los lipes y atacamas "por ser colindantes con los de guerra" y por "temor a que se alzasen" 4 , tema que también repite Lozano Machuca en su descripción general sobre los lipes y los grupos vecinos (1885 [1581]: 24). Lizárraga menciona que "los indios de Atacama han estado hasta agora medio de paz y medio de guerra; son muy belicosos" (1987: 148) y de los lipes se señala "que no eran tan belicosos como se decía" (Lozano Machuca 1885 [1581]: 22). El diálogo entre un discurso oral y social y una determinada textualidad pareciera continuar. Aquí ya no se trata de la probanza de méritos de los Altamirano o de otro encomendero, pero el enunciado está igualmente presente y la referencia pareciera operar con similar eficacia.

De las situaciones de conflicto que dieron lugar a esas expresiones dan cuenta, obviamente, los mismos procesos de pacificación de Casabindo, de Atacama y de Humahuaca que relatan estos documentos, así como las continuas entradas de capitanes españoles a la región y las sucesivas fundaciones y refundaciones de pueblos (Téllez 1984, 1989; Lorandi y Boixados 1987-88; Lorandi 1988; entre otros), y las reiteradas sublevaciones indígenas capitaneadas por Viltipoco (Gentile 1988) o por Calchaqui. Sin embargo, esa

3 AGI Charcas 80 f. 18r; AGI Patronato 188 n $^{\circ} 4$ f. 2 r; AGI Patronato $188 \mathrm{n}^{\circ} 1 \mathrm{f}$. 1v; AGI Charcas 80 f. 19r; Ibíd., f. 21r; AGI Charcas 80 f. 28r; Ibíd., f. 28v; Ibíd., f. 29r. Las referencias siguen el orden de las citas en el texto.

4 Carta del virrey Toledo al rey, La Plata 30 de noviembre de 1573; Levillier 1924, t. V: 240. "tierra" también es un espacio de refugio, pues allí acuden Martín Monje, encomendero de Casabindo y Hernán Núñez, encomendero de los Lipes, a esconderse de Gonzalo Pizarro ${ }^{5}$, e innumerables grupos de españoles la cruzan de un extremo al otro y en ambos sentidos, organizando rutas comerciales e intercambiando productos con los mismos indios. ${ }^{6}$ Más aún, hay españoles que residen o han residido entre estos grupos, como el cura Esteban Justiniano, quien vivió en el valle de Atacama durante seis años y que insiste, sin embargo, que es "gente muy velicossa" (AGI Charcas 80, f. 83v.). Situaciones que, sin embargo, no parecen entrar en contradicción -en cuanto a discursividad- al interior del texto con el enunciado "la tierra rebelada".

Sospecho entonces que ese enunciado (con todo lo que implica), pudiera estar configurando una etiqueta descriptiva, una referencia cuyos signos y componentes serían compartidos por la burocracia y los potenciales lectores de un documento, y no una descripción que pretenda corresponder exactamente con una "realidad", lo que parece implicar efectos concretos en la textualidad de los documentos. Y tengo la impresión de que lo que empieza a surgir de estos documentos es un posible sistema de clasificación, expresado por las diferencias en los signos lingüísticos, por el cual el pensamiento hispano podría organizar una determinada descripción de ciertos grupos indígenas. ¿Es posible pesquisarlo y visualizar sus alcances?, ¿cuándo surge?

En otros textos más tempranos, relativos a la primera mitad del siglo XVI, la crónica de Bibar (1558) y la de Fernández de Oviedo que describe el paso de Almagro (1549), por ejemplo, o las declaraciones

\footnotetext{
5 AGI Patronato 137 doc. 1 ramo 11, AGI Patronato 95-B ramo 6.

6 AGI Patronato 29 ramo 39, año 1587.

7 Es al enfrentarnos a este tipo de problemas cuando se advierten con mayor claridad -en el caso de los estudios sobre los espacios andinos más meridionales-, las diferencias entre nuestro conocimiento etnohistórico sobre las sociedades indígenas y el conocimiento "etnohistórico" sobre la sociedad europea, a pesar de trabajos pioneros como los de Barnadas para Charcas (1973) y Lorandi para Tucumán (1988Ms y 1991Ms). Desconocemos, por ejemplo, las dimensiones que pudo haber alcanzado el uso de un lenguaje diferencial con el cual los documentos refieren hechos o situaciones bajo nombres distintos, según se trate de actores indígenas o europeos (los enfrentamientos entre españoles son "batallas", en tanto que los mismos enfrentamientos, pero esta vez contra grupos indígenas, son usualmente denominados "encuentros", "guazabaras", etc.).
} 
de los acompañantes de Pedro de Valdivia, que llega a Atacama en 1540 y Francisco de Aguirre que pasa por Tucumán y Atacama en esos mismos años (Medina 1896-1900; Silva Lezaeta 1953), esta caracterización no tiene el peso que parece adquirir más tarde; más aún, podríamos señalar que está ausente. Tanto Almagro como Valdivia y Aguirre tuvieron enfrentamientos con diversos grupos de la región, no sólo con los atacamas, sin embargo no los caracterizan como "de guerra" ni su relato sobre "la tierra" está estructurado por el alzamiento. Lo que queda por pesquisar aún, en este caso, es si ello da lugar al tratamiento o descripción de situaciones diferentes, por lo tanto a una información documental distinta en sus contenidos y organización, que quedarían excluidas al imponerse el discurso sobre "la tierra alzada".

\section{"La tierra áspera y fragosa"}

¿Cómo funciona el enunciado?, ¿qué es lo que contribuye a describir?, ¿qué es lo que se enuncia?, ¿cuáles son sus signos? La "tierra" es uno de ellos y se revela plena de significados (geográficos, físicos, astronómicos, etc.), que sería demasiado extenso referir aquí por lo que me detendré en uno, aquel que parece permitir una mejor aproximación a esa expresión de "la tierra rebelada". Junto con significar cualquier región, territorio o pueblo, "la tierra" significa también el conjunto de habitantes de un territorio (Montaner y Simón 1912: 921; RAE 1970; Casares 1989: 813; ). Expresiones tales como "partir la tierra" (dividir una población), "que no lo sienta la tierra", "correr la tierra" o "la tierra rebelada" usadas en diferentes textos y expresiones del siglo XVI, muestran este significado. En ellas se habla de los habitantes, pero también simultáneamente del espacio, del territorio, sugiriendo así con esa homologación, la existencia de un vínculo entre esa tierra y sus habitantes: los hombres que la pueblan son también, de alguna manera, la tierra.

Es un uso del lenguaje que recuerda fuertemente el tema de la semejanza, en cuanto al lugar que ella ocupaba como principio constructivo del saber durante el siglo XVI, organizando el juego de los símbolos y dirigiendo el arte de la representación (Foucault 1989: 26):

"Dentro de la amplia sintaxis del mundo, los diferentes seres se ajustan unos a otros; la planta se comunica con la bestia, la tierra con el mar, el hombre con todo lo que lo rodea. La semejanza impone vecindades que, a su vez, aseguran semejanzas. El lugar y la similitud se enmarañan: se ve musgo sobre las conchas, plantas en las cornamentas de los ciervos, especie de hierba sobre el rostro de los hombres..." (Foucault 1989: 27).

Puesto que existe una semejanza, entre unos y otra pueden trasvasijarse características, actitudes, gestos. Es tal vez por ello que la tierra puede ser de guerra, como sus habitantes, puede alzar como ellos (AGI Charcas 80) y éstos pueden, a su vez, "coserse con la tierra", es decir unirse estrechamente a ella (Montaner y Simón 1912).

En los textos con los cuales estamos trabajando, hemos podido ubicar un conjunto de términos, verdaderos atributos que parecen acompañar a la expresión "la tierra de guerra" o "rebelada" y que de una u otra forma parecieran servir tanto de sinónimos como de significantes con contenido propio. Aunque aún no estoy seguro de todas sus posibilidades de ordenamiento, combinación o sustitución, se puede ver, por ejemplo, que la "tierra alzada" o "tierra de guerra" (AGI Charcas 80, f. 19r) implica que ella sea también descrita como "cerrada", y que sea caracterizada como "áspera" y "fragosa", lo que contrasta muy claramente con un grupo de términos opuestos, empleados cuando la tierra está "quieta y pacífica", puesto que entonces ella es "llana" y está "abierta". 9

La "tierra" pareciera cambiar cuando cambian las actitudes de sus habitantes. Esto es importante puesto que lo que inicialmente podría ser leído como una simple descripción de un paisaje (caminos ásperos y difíciles, lugares lejanos, etc.), puede transformarse de pronto, por los vínculos que establece la semejanza y por los juegos que permite la polisemia, más bien en un relato cargado de símbolos y categorías que en un reflejo de la topografía. $O$ en una topografía cargada de significados que están más allá que su referente.

Detengámonos un momento en los atributos del sujeto tierra rebelada. Los significados políticos que hoy damos al "alzado" tienen el sentido del acto de levantarse quien estaba postrado o aplastado, una lectura actual posible, pero no la única en esta expresión. "Alzar" era también "formar prominencia"

\footnotetext{
AGI Charcas 80, fs. 18r, 30v, 31r, 34r.

AGI Charcas 80 fs. 18r, 19v.
} 
y "fugarse y hacerse montaraz el animal doméstico" (Casares 1989: 43). Esta última acepción alude más claramente a los contenidos políticos que en el siglo XVI podría tener la expresión "los indios alzados" y volveremos sobre ella más adelante ${ }^{10}$, pero ninguna de estas lecturas posibles da cuenta de "formar prominencia" como significado. Es decir, hacer desigual lo que no lo era; una prominencia interrumpe la continuidad de un terreno, de algo considerado liso. ¿La paz social, en el siglo XVI, era pensada como un espacio sin protuberancias, sin contradicciones, algo que lo alzado venía a romper? Esta última lectura me parece se apoya también en los otros términos que hemos extraído de los documentos: una de las características de lo "áspero" es, precisamente, su superficie desigual que le resta suavidad al tacto. Y lo "fragoso" es un espacio pleno de diferencias morfológicas. La tierra alzada aquí puede ser leída, entonces, como lo desigual, lo discontinuo.

El atributo de "cerrada" pareciera más oscuro. Cerrado es aquello que nos impide el paso y, en ese sentido, puede aludir a las dificultades de tránsito como resultado de una sublevación, "el camino cerrado y tomados los pasos", por ejemplo (AGI Charcas 80, f. 29r), pero uno de los significados de "allanar" o "pacificar" es "dar entrada a la justicia en algún lugar cerrado" (Casares 1989: 43). Es decir, que lo cerrado estaría aludiendo aquí, entre otros significados, a una condición social y política: la ausencia de justicia. Lo que puede ayudarnos a comprender mejor, entonces, por qué el camino "estaua serrado con las muertes robos e ynsultos caussados por los yndios" (AGI Charcas 80, f. 18r). Los "ynsulto" pueden cerrar un camino en cuanto ellos significarían, precisamente, la ausencia de justicia, junto con los robos y las muertes. La tierra de guerra entonces, parece caracterizada como lo desigual (alzada, fragosa, áspera) y asocial (cerrada como carencia de justicia). Descripción que pareciera aludir no a un paisaje, a un relieve geográfico, sino a la representación simbólica de un espacio social y político cuya característica hemos señalado.

Pacificar, por el contrario, es "allanar", hacer llano o liso aquello que era áspero y desigual. "Allanar" es un término de amplia difusión en la documentación

10 Hay una interesante diferencia de sentido entre ambas acepciones, puesto que la más moderna alude a una postración inicial, alzarse como sinónimo de "erguirse"; en tanto que la segunda apunta más bien a la pérdida de lo social como atributo: "hacerse montaraz". colonial y entre sus significados además de "pacificar" y "dar entrada a la justicia en algún lugar cerrado", está el de "igualarse a la plebe el que es de más elevada condición" (Casares 1989: 43). Es decir, se "allana" aplanando, hacia abajo, eliminando las diferencias y abriendo un espacio cerrado, imponiendo en definitiva una determinada igualdad, eliminando la discontinuidad e introduciendo la justicia. El espacio simbólico resultante se organiza con las categorías contrarias a las de la guerra indígena: lo igualado, lo continuo, lo social.

El lenguaje documental español aparece entonces usando la naturaleza para metaforizar determinados aspectos de la relación hispano-indígena. "Abierta vs. cerrada" y "fragosa vs. llana" pueden sintetizarse en la relación "continuidad-discontinuidad" y "social-asocial", que operarían aparentemente como una estructura elemental de significación (Greimas 1987: 30), permitiendo expresar tanto la situación de belicosidad indígena como su pacificación y organizando las categorías descriptivas que darían cuenta de ellas. Pero este campo semántico que empezamos a entrever no se agota, ciertamente, aquí.

En el relato de los procesos de pacificación se advierte el uso reiterado de algunas expresiones, empleadas para mencionar el momento en el cual los grupos indígenas o sus dirigentes aceptan la paz. Los títulos de dos de los documentos del conjunto que comentamos emplean una misma expresión para señalar la aceptación indígena de la pacificación: "Como venieron de paz los yndios de Casabindo e se bautizaron el cazique su muger e hijos" y "Diligencias que se hizieron con los yndios de Atacama que estaban de guerra para que veniesen como vinieron a la obediencia e servicio de su magestad".

Las relaciones intertextuales se perciben fácilmente aquí; el discurso, el empleo similar de expresiones se repite en otros documentos que hablan de éstos y otros grupos indígenas. En 1550, Juan Núñez de Prado declaraba que:

“... estando junto al pueblo de Tiparo aloxado ques veynte e quatro leguas desta cibdad [del Barco] me dixo un caçique atacama que me había salido de paz..." (BNBA Col. GGV, doc. 1234 p. 2).

“...y dizen los dichos yndios que están aleados y de guerra que hasta que yo vaya a los gobernar no an de servir ni salir de paz..." (García Hurtado de Mendoza a Juan Pérez de Zurita, en Lorandi y Bunster 1987-88: 240). 
"Salir de paz" o "sacar de paz", se repite en la probanza de méritos de Françisco Altamirano, quien señalaba haber sacado de paz a Viltipoco, dirigente atacama asentado en Humahuaca ${ }^{11}$, lo que también refiere su padre Juan Velázquez Altamirano, quien "sacó los yndios de Atacama de paz". ${ }^{12}$ Son expresiones que parecen reafirmarse cuando, para referirse a la misma situación, un testigo declara que don Françisco Altamirano: "traxo de paz a don Diego Viltipoco y a sus yndios y a los de Omaguaca que era capitan de toda aquella provincia que estauan alzados y reuelados" (AGI Charcas 80, f. 30r). Velázquez Altamirano también señala que a los atacamas los traxe de paz e hize poblar en el camino real e an estado pacificos y quietos hasta oy" (AGI Charcas 80, f. 37v), y en su declaración como testigo, Polo de Ondegardo emplea la misma expresión "traer de paz" (AGI Charcas 80, f. 42r). Expresión usada también en otra probanza de méritos, la de Juan Núñez de Prado, quien señala asimismo que estuvo "conquistando e trayendo los caçiques e naturales de paz" (BNBA Col. GGV doc. 1234, p. 2).

"Salir", "venir", "sacar", "traer", ¿de dónde? Los indios "salen" o "vienen" de, o son "sacados" o "traídos", expresiones que, sospecho, no tienen una implicancia geográfica directa, puesto que de lo que aquí se está hablando es de actitudes y acciones políticas (estar "de guerra" o aceptar la paz) y no lugares. La direccionalidad de la acción parece clara: se trataría de "traer", hacia adentro, lo que ha estado afuera o ha ocupado un espacio diferente. Si esta suposición es correcta, al "estar de guerra" los grupos indígenas ocuparían simbólicamente un determinado espacio social, del cual podrían "salir" o ser "sacados", ingresando así a un nuevo espacio, el socializado o pacificado (igualado). ¿Se puede pensar en una nueva estructura elemental de significación empleada para referirse a estos grupos, esta vez articulada por un "adentro-afuera"? En este caso, ¿afuera de qué o de dónde?, ¿qué espacialidad es significada?

Esta aproximación es aún demasiado incipiente para disponer de una textualidad más amplia que permita pesquisar todas las dimensiones posibles de ambos espacios sociales. En principio, el "afuera"

11 AGI Charcas 80, fs. 15r, 22v, 26v.

12 AGI Charcas 80, f. 26v-27r, todos los subrayados de estas citas son nuestros. tiene connotaciones políticas, tal como se desprende de las afirmaciones de algunos testigos. Polo de Ondegardo declaraba:

"A la septima pregunta dixo que este testigo saue que los yndios de Atacama auia muchos años que estauan reuelados y fuera de la ovediencia de su magestad..." (AGI Charcas 80, f. 41v, el énfasis es nuestro).

Afirmación que es repetida por Martín Monje:

"A la dezima pregunta dixo que este testigo saue e a uisto que el dicho Joan Uelasquez Altamirano a hecho e haze muy buen tratamiento a los caciques e yndios del // [f. 52r] dicho repartimiento de Atacama por lo qual los dichos yndios casso que estén poblados en comarca de gente de guerra están quietos y pacificos poblados en el camino real que va a las prouincias de Chile y en su comarca ay muchos yndios aleados e reuelados fuera de la obediencia real de su magestad e que esto responde a ella e lo demás no lo saue" (AGI Charcas 80, f. 51 v-52r).

Es desde una tierra "fragosa" y "áspera" (discontinua, asocial), de donde, me parece, salen o son sacados o traídos los "indios de guerra" para ser "poblados" en tierra "llana, quieta y pacífica", para entrar "dentro" de la obediencia al rey. Pero "afuera" es, también, lo montaraz, lo salvaje. Recordemos ese sentido expresado en "alzar": "fugarse y hacerse montaraz el animal doméstico". En ese caso aparecería expresada la direccionalidad opuesta, "alzarse" sería "irse" hacia afuera, es lo doméstico que se hace salvaje, esto es, un proceso de pérdida de la socialización, ¿el hombre "alzado" deja así de ser "hombre"? Al "sacar" o "salir" del espacio de "afuera", se efectuaría, por el contrario, el proceso de socializar. Un discurso, en definitiva, que permite expresar que los indios pacificados están amansados como a gente recién reducida, es decir, se les ha arrebatado su condición de "salvajes" y no domésticos ${ }^{13}$, han sido transformados en hombres sociales (AGI Charcas 80, f. 37v).

El mundo de "adentro" aparece entonces como el paradigma, allí se está "debaxo de la obediencia e

\footnotetext{
13 Intuyo que en títulos tales como "Arauco domado" de Pedro de Oña, pudieran estar operando elementos de esta discursividad y de su sistema clasificatorio.
} 
amparo e seguro real", siendo por lo tanto un mundo esencialmente seguro, allí los grupos indígenas pueden esperar "justicia y amparo". ${ }^{14}$ Es un mundo "abierto", como ya lo vimos, a la justicia, obediencia, amparo y seguro, todos valores de lo social, de lo ordenado. Se trataría, en una u otra forma, de un mundo que se pretende sin contradicciones, donde lo desigual ha sido ya igualado.

A lo largo de toda esta exposición hemos sentido que el lenguaje empleado en los textos se mueve, constantemente, entre un plano que, por ahora, llamaré "de lo real", que parece tener referencias concretas (un paisaje, una rebelión) y otro plano, en el que cada una de esas palabras parece poseer además otros sentidos, que remiten a un discurso que está más allá del texto mismo y que contribuye a organizar las descripciones. Es una sensación que se acentúa cuando son significados otros posibles aspectos de estos espacios de "adentro" y "afuera".

La descripción de los grupos involucrados en la tierra de guerra, por ejemplo, conlleva repetidamente cierta ambigüedad: por un lado, mencionan explícitamente a determinados grupos (humahuacas, atacamas, casavindos, etc.), pero generalmente hay, en torno a ellos, grupos innombrados. Los atacamas [os] "aueis aleado y traido con vos y en vuestra compañía algunos caçiques e yndios vuestros comarcanos". Françisco Altamirano "traxo de paz los caciques e yndios de Omaguacas otros". ${ }^{15}$ Expresiones tales como "otros indios", "comarcanos", "circunvecinos", o "muchos indios", "cercanos a" o que "confinan con", etc., que podrían ser leídas superficialmente como descripciones objetivas de una distancia geográfica son referencias, me parece, a límites o bordes imprecisos. Se trataría de un espacio de "afuera" con fronteras de difícil percepción y esto no parece casual; es el espacio de lo discontinuo, lo desigual. Es, también, un espacio físicamente próximo pero de manera simbólica distante, ubicado en forma reiterada en los "confines", un espacio cuya geografía es siempre difícil y cuya población es dispersa.

“... por ser yndios mesclados con los de guerra y estar muy lejos desta ciudad nunca an sido tassados ni dan mas que lo que ellos quieren..." (AGI Charcas 80, f. 2Ir).

14 AGI Patronato $188 \mathrm{n}^{\circ} 4$ f. 1r; AGI Charcas 80 f. 68 r.

15 AGi Patronato $188 \mathrm{n}^{\circ} 4$ f. 2r; AGI Charcas 80 f. 18 r.
“... tiene por cierto que son mas de dos mili yndios e por estar lexos de la çibdad de La Plata an estado mucho tiempo de guerra..." (BNBA Col. GGV, doc. 1400-6, p. 27).

“...porque siempre an estado ynquietos e no muy pacificos e que no se an podido reducir por estar en partes tan remotas y apartadas como en la provincia de Atacama..." (AGI Charcas 80, f. 107r).

Son las mismas expresiones, similares atributos y descripciones las que emplea Lozano Machuca en su descripción de los indios lipes y grupos vecinos:

“... hay otros indios que confinan con los indios de guerra de Omaguacas y Casavindos, y tienen trato y comercio con estos lipes, los cuales están neutrales, que no son ni de paz ni de guerra y entran en Potosi con nombre de indios lipes y atacamas con ganados y otras cosas de venta y rescate..." (subrayados nuestros, Lozano Machuca 1885 [1581]: XXIV).

¿Cómo desechar la intuición de que éstas son palabras transformadas en "marcas", que organizan y ordenan una descripción, que revelan una suerte de otro paisaje $\mathrm{y}$ de un discurso diferente: el de los espacios entre los cuales pueden moverse los hombres?

En un trabajo anterior (Martínez 1991), empleando la estrategia tradicional de aproximación a los documentos que he referido al inicio de este trabajo, privilegié las posibles connotaciones sobre las tácticas étnicas que este mismo párrafo parecía sugerir, pero el presente análisis, que surge de documentos muy distintos a la relación del Factor de Potosí, me hace dudar actualmente de la corrección de esa lectura, puesto que la ambigüedad étnica no parece tan distante de la simbolización de los límites y características asignadas al espacio de "afuera".

En definitiva, ¿qué se relata, qué se describe?, ¿la geografía física o la simbólica de un espacio conceptualmente salvaje, asocial y desordenado? ¿Hasta qué punto la dispersión territorial de estos grupos corresponde con una práctica social concreta en esta región y dónde empieza el efecto de discursividad -la necesidad de señalarlos como territorialmente dispersos-, puesto que son lo opuesto a los grupos reducidos, asentados o poblados, ya ordenados y pacificados? Pareciera que las exigencias narrativas de un relato socialmente "marcado" se imponen, por decirlo de alguna manera, a las de la "verdad". Que 
lo verosímil no está dado por su vinculación estrecha con "lo real", sino con "lo creíble", con una forma establecida de antemano de "decir".

Sin afirmarlo enfáticamente, pareciera que incluso algo tan aparentemente despojado de significación como el "camino real" pudiera ser empleado también como una de las expresiones posibles del "adentro", del espacio pacificado y ordenado bajo la corona, lo opuesto a una dispersión.

Los humahuacas, en proceso de pacificación, "han salido y salen y dan auiamiento y comidas a los pasaxeros" que transitan por el camino real, es decir, se sale al camino (AGI Charcas 80, f. 15r). Velázquez Altamirano señala que a los atacamas "los traxe de paz e hize poblar en el camino real tomo los demás e an estado paçificos y quietos hasta oy" (AGI Charcas 80, f. $37 \mathrm{v}$ ) y la permuta de la encomienda de Atacama se hace, precisamente, con la excusa de poblarlos y asentarlos en el camino real (BNBA Col. GGV doc. 1400). Pero es obvio que no todas las poblaciones indígenas asentadas y reducidas están sobre el camino real, por lo que, nuevamente, la expresión pareciera contener un sentido que puede apoyarse en un "dato" de la geografía política, pero que va más allá de su significación geográfica.

Hasta aquí, el enunciado "la tierra rebelada y los indios alzados" se muestra como parte de un discurso que permite ordenar o encasillar a los grupos indígenas, según sean éstos de paz o de guerra. Un enunciado doblemente significativo, puesto que a la significación de las palabras le agrega nuevos sentidos y connotaciones, permitiendo el empleo de algunos términos y marginando otros, provocando también consecuencias en el relato que se hace sobre cada grupo indígena, clasificándolos y otorgándoles determinadas características sociales y culturales de acuerdo a sus actitudes políticas.

Así, la descripción de las sociedades indígenas, ya se habrá advertido, puede también estar fuertemente condicionada por la valoración previa de sus actitudes de acatamiento o rebeldía, al menos en este tipo de textos. No debe extrañarnos, entonces, que las categorías empleadas para referirse a los grupos indígenas según ocupen una u otra de las opciones políticas, permanezcan dentro del mismo cuadro de oposiciones binarias que hemos venido estableciendo (Cuadro 1).

\begin{tabular}{|l|l|}
\hline Adentro & Afuera \\
\hline orden & desorden \\
\hline domesticado & salvaje \\
\hline social & asocial \\
\hline continuo & discontinuo \\
\hline cercano (¿centro?) & lejano \\
\hline
\end{tabular}

Cuadro 1. Los espacios.

Indios "alzados y de guerra" $v s$. indios "quietos y pacíficos", dispersos territorialmente $v s$. "asentados y poblados en el camino real"; alzados vs. reducidos, salvajes vs. "domados", etc., son expresiones que parecen acompañar a cada uno de los conjuntos de atributos que rodean a las proposiciones "afueraadentro", planteando fuertemente la continuidad de los efectos de esta representación en la discursividad de los textos.

"A la dezima pregunta dixo que este testigo saue que todos los comarcanos de Atacama están alçados y de guerra como son los yndios de Calchaqui e apatamas e omaguacas" (AGI Charcas 80, f. 43r).

"estauan alçados y de guerra e como tales matauan muchos españoles que passauan por su tierra" (Charcas 80, f. 67r).

"si el dicho Joan Uelasquez no estuuiera de por medio según son de uelicossos los dichos yndios y estar como están sus comarcanos con quien ellos tratan todos yndios de guerra y uelicossos se ouieran aleado y reuelado como lo estauan de antes" (Charcas 80, f. 68v). ${ }^{16}$

"Alzados y de guerra" es más que una simple afirmación que pretenda describir una determinada realidad sociopolítica; su sola reiteración sin cambios en la sintaxis, demuestra el empleo de ciertas categorías establecidas de antemano, usadas para describir determinadas prácticas. Hay, por otra parte, una flexión en esa expresión que es muy sugerente: los indios están de guerra, pero también son de guerra, lo que se complementa con otros atributos que despliegan ante el lector un pequeño tratado clasificatorio: son "belicosos", "poco seguros" e "inquietos", "으o tales [alzados y de guerra] matauan muchos españoles", etc. Frente a ellos se yergue, patética, la denominación de quienes ya vinieron de paz: "indios

16 Ver también, por ejemplo, AGI Charcas 80 fs. 3v, 25v, 27r, 38r, 64v, 65v; AGI Patronato 137 doc. 1 ramo 11 f. 2v. 
quietos y pacíficos", "asentados" y "sustentados y amansados como a gente recién reducida". ${ }^{17}$

El término "reducidos" permite oponer, en los textos, a aquellos que ya han "venido" de paz con quienes aún están "alzados". ¿Cuál es su relación? Los diferentes significados de reducir pueden sintetizarse, básicamente, en cuatro sentidos: a) disminuir algo, aminorarlo o empequeñecerlo de tamaño, b) cambiar una cosa por otra que se considere equivalente, c) sujetar a la obediencia a los que se habían separado de ella y d) traer, a una sola especie, cantidades de especies distintas (Montaner y Simón 1912: 277278). Recordemos que alzarse implicaba "irse" de lo social para volverse montaraz, tema que vuelve a aparecer en reducir, puesto que permite expresar el retorno a la obediencia (estar adentro, si volvemos a la expresión "alzados = fuera de la obediencia"), de quienes, precisamente, se "han ido". Pero, ¿qué vínculos establece el pensamiento español entre esto y acciones tales como disminuir, cambiar de estado una cosa o reunir en uno lo que originalmente sería diferente? ¿Por qué reducir es un término político? Creo que una posible clave de comprensión está sugerida por el acto de "traer a uno" lo originalmente distinto, es decir, de igualar lo diferente, lo que puede hacerse estableciendo equivalencias, igualdades. ¿Acaso lo que se disminuye o reduce de tamaño son las "protuberancias", las discontinuidades generadas por el alzado, después de que han sido establecidas equivalencias que permiten la igualación? Contenidos de gran proximidad con allanar y que nos remiten al punto de inicio del enunciado, a los contenidos expuestos en "la tierra". ¿El alzado se hace diferente $\mathrm{y}$ debe ser reducido nuevamente a una igualdad? ¿O para que se produzca ese paso debe existir previamente una equivalencia establecida?

La pesquisa de las posibles asociaciones establecidas por la oposición "salvaje-doméstico" es aún una tarea pendiente, limitada en este caso por lo pequeño del conjunto documental que dio origen a este análisis, pero sería extremadamente interesante investigar si de esa clasificación no se desprenden también otras valoraciones, tales como la oposición caza-agricultura, u otras caracterizaciones culturales sobre cada uno de los grupos (Cuadro 2).

17 Charcas 80 fs. 38v, 43r, 84r; Charcas 80 , f. $37 \mathrm{v}$.

\begin{tabular}{|l|l|}
\hline de guerra & salidos de paz \\
\hline belicosos & pacíficos \\
\hline inquietos & quietos \\
\hline alzados, rebelados & reducidos \\
\hline dispersos & asentados \\
\hline salvajes & amansados, domados \\
\hline
\end{tabular}

Cuadro 2. Los indios. Atributos clasificatorios aplicados a los grupos indígenas de acuerdo a su aceptación o rechazo de dominio colonial.

Los atributos asignados a los indios de guerra son coherentes con los contenidos que hemos revisado en las otras expresiones que conforman el enunciado "la tierra alzada y los indios rebelados". "Belicosos, inquietos, salvajes" alude a un contenido de asocialidad, así como "alzados, dispersos y con límites sociales y geográficos imprecisos" pareciera referir a lo discontinuo y al desorden.

Pero "adentro-afuera" y todo el ordenamiento binario que exploramos no parecen ser sino la expresión primera de una categorización mayor de esos espacios, que me atrevería a expresar como "Sociedad vs. Naturaleza" y que es la que, en el fondo, les proporciona el sentido. El Cuadro 3 puede ayudar a ordenar los términos revisados:

\begin{tabular}{|l|l|}
\hline Naturaleza & Sociedad \\
\hline afuera & adentro \\
\hline lejano & cercano \\
\hline salvaje & domesticado \\
\hline discontinuo & continuo \\
\hline desorden & orden \\
\hline asocial & social \\
\hline
\end{tabular}

Cuadro 3. Los espacios del mundo.

Así, al menos dentro del contexto de este enunciado, pareciera que el relato documental de la probanza de méritos que ha constituido la columna central de nuestro análisis, giraría más en torno a una preocupación sobre los "mundos posibles", sobre los espacios entre los cuales pueden fluctuar los hombres, aquellos ámbitos sociales a los que pueden ser reducidos, que sobre los procesos de pacificación; lo que implicaría que, en tanto procesos políticos, su relato estaría sometido a un poderoso esfuerzo de significación. En este sentido, éste es, esencialmente, 
un discurso cultural más que una descripción histórica. Sería peligroso, en esta perspectiva, pretender entonces hacer una "historia" de los procesos de pacificación.

Si de lo que trata este enunciado es básicamente una reflexión sobre la oposición política de la sociedad frente a la naturaleza, visualizadas como los espacios del hombre, es evidente que ello debería llevar a una revisión necesaria sobre el papel del pacificador, sobre el discurso elaborado por los capitanes españoles en sus probanzas de méritos, en la organización de sus relatos. La figura del pacificador, como protagonista arquetípico de un relato, pareciera guardar en una aproximación aún superficial, un interesante paralelo con la figura del "héroe" de algunos cuentos populares europeos, en tanto que intermediario entre dos espacios y restablecedor de un equilibrio alterado por una ruptura inicial, sugiriendo así nuevas luces y caminos para entender la estructura discursiva de documentos tales como las probanzas de méritos. Desgraciadamente, su exposición nos llevaría hacia otros derroteros, por lo que la dejaremos pendiente para un próximo trabajo.

\section{Textos y palabras}

¿Cómo cerrar una lectura sobre unos textos que, ya lo han demostrado, son abiertos; son documentos cuyo fin no está en ellos, sino en una determinada discursividad que está más allá que ellos mismos? Nuestra aproximación es demasiado inicial y reducida como para pretender que ella tenga validez más allá de los límites de esta textualidad y de este trabajo, pero tiene el valor de sugerir la necesidad de profundizar nuestro conocimiento sobre los documentos, de pensarlos y abordarlos como un tipo de relato, como textos referenciales. Y aquí quisiera destacar dos elementos que me parecen metodológicamente centrales: por una parte, lo que llamaré, siguiendo a Barthes, el volumen de los textos y, por otra, el lenguaje de éstos, sus palabras.

Al finalizar la lectura de un documento se tiene, a veces, la sensación de que, a pesar de su singularidad, él forma parte de una vasta red de textos, de una trama siempre mayor de palabras, enunciados y discursos y que, por lo tanto, gran parte de su propia significación no está precisamente en lo que dice, sino en su inclusión en ese tejido, en las relaciones establecidas de antemano -incluso aún antes de ser escrito-con otros textos. Que tanto quienes escriben como quienes relatan algo están constantemente remitiéndose a una dimensión no directamente representada en el manuscrito, a unas relaciones o a un discurso que, aunque ausente, igualmente contribuye a darle sentido a sus propias palabras. Se tiene, asimismo, la impresión de que una parte importante de esas palabras, de sus "decires", se remiten precisamente a esos otros textos, que encuentran su sentido por presencia u omisión. También, que por muchos intersticios se cuelan otras voces. En definitiva que, por lo tanto, ese manuscrito puede ser un punto de articulación de muchos significados y sentidos, que dialoga no sólo con el relato, con lo que supuestamente narra, sino también con lo que otros han dicho anteriormente.

"Un relato no es un espacio tabular, una estructura plana, es un volumen, una estereofonía [...]; hay un campo de escucha del relato escrito; el modo de presencia del sentido (salvo quizá para las secuencias accionales) no es el desarrollo, sino el estallido: llamadas de contacto, de comunicación, posiciones de contrato, de intercambio, estallido de las referencias, de fulgores de saber, golpes más sordos, más penetrantes, venidos de la 'otra escena', la de lo simbólico, ..." (Barthes 1990: 351).

Un volumen. El texto como una malla con sus propias dimensiones, con fragmentos más profundos y densos que otros, con estrategias y discursividades que lo articulan, pero a la vez, lo reorganizan en unidades menores. Ciertamente me estoy refiriendo a metáforas, pero si de ellas se trata, también hay una metáfora implícita operando detrás de las estrategias heterogéneas: la del documento como un plano, como un velo que es posible traspasar para aprehender realidades que están "detrás" de él. Y el volumen de estos textos parece imponer su pesada presencia, parece "gritar" su existencia y exigir, con ello, la necesidad de repensar las aproximaciones posibles.

En la relación del etnohistoriador con los textos, nos vemos obligados a desplazarnos constantemente entre dos relatos diferentes. Uno, que llamaré discurso descriptivo I siguiendo a Calame (1990: 115 y ss.), constituido básicamente por nuestras fuentes documentales y sobre el cual tenemos una determinada conciencia explícita de ser "operadores", de que trabajamos con él, y un discurso descriptivo II, el nuestro, sobre el cual hay una muy escasa reflexión y que generalmente se asume en una relación de transparencia con el discurso I. Como si nuestro propio relato reorganizador (ese que resulta de la suma de los datos extraídos de un corpus heterogéneo), no constituyese sino el orden "natural", 
el mejor orden posible de esos datos extraídos a pesar del documento, pero que, en su constitución, no los alteran ni transforman su sentido, puesto que resultan de una lectura que "traspasa" lo escrito para alcanzar la dimensión de lo dicho. Las relaciones entre ambos discursos, el que surge del volumen de los textos y que parece envolver y dificultar la aproximación a las sociedades indígenas, y el nuestro, que muchas veces ignora ese volumen y permanece atrapado en él, sin percatarse, deben ser igualmente profundizadas.

Muchos análisis documentales (particularmente los relativos a las crónicas) se apoyan en el implícito de que al interior de un texto subyace un solo discurso, por lo que la información que proporcionan es utilizable en diferentes contextos. Se trata de otro supuesto que, me parece, debe ser analizado, puesto que, ¿qué pasa cuando es posible detectar la existencia simultánea de varios discursos, de diferentes ordenamientos descriptivos al interior de un mismo relato?, ¿qué procedimientos de análisis requieren y cuáles son los "datos" que podemos extraer de allí? Cierto, hay enunciados, como el que acabamos de ver, que parecen atravesar una variedad de textos, pero, ¿cuántos enunciados, con sus propias reglas y su particular manera de organizar el relato coexisten dentro de un mismo texto? ¿Cómo opera una determinada discursividad?

Esta situación implica claramente un llamado de atención sobre aquella estrategia heterogénea de investigación a la que nos referíamos inicialmente, puesto que cada uno de estos discursos parece organizar y emplear a su propia manera los elementos que constituyen nuestros datos. Creo que también implica, asimismo, una prevención a las posibilidades de una reconstrucción etnográfica tal como se ha venido realizando hasta ahora y que deberá ser revisada si las aproximaciones logradas aquí pueden ser extendidas hacia otros tipos de textos y discursividades.

Salvando todas las diferencias, el lenguaje de estos textos parece operar constantemente en un doble plano de sentido, que recuerda en algo a las estructuras míticas, refiriéndose a una "realidad", pero usándola a su vez para producir una significación que va más allá de las intenciones descriptivas del relato, de la adscripción estricta a los hechos históricos. Es decir, enunciados que se apoyan sobre algunos puntos o aspectos de una "realidad", pero que a su vez la organizan simbólicamente para poder referirse a ella. Ciertamente hay un Camino Real, pero éste denota simultáneamente el espacio social ordenado; la geografía puede ser fragosa o áspera, pero es el espacio de lo social y político lo que se allana; puede que realmente los grupos indígenas estuvieran dispersos por un amplio territorio, pero esa dispersión es también un atributo culturalmente asignado a esos grupos y es eso lo que se pareciera remarcar; los grupos indígenas están efectivamente "alzados", pero detrás del término hay todo un discurso sobre la política, etc.

En este discurso las palabras son verdaderos signos, operan como "marcas" de un paisaje social, en que cada una de ellas remite, casi automáticamente a otras, pero en forma simultánea contribuyen a tejer una toponimia social, a atribuir rasgos, posiciones, actitudes, etc. Se produce en todo esto un juego entre "lo real" y "lo verosímil" que aún no estamos en condiciones de perfilar. ¿En qué momentos el relato sobre lo real está determinado por lo verosímil y cuándo se produce la situación inversa?

"La tierra reuelada y los yndios alçados" es, en esta perspectiva de aproximación, un enunciado cuyos referentes no provienen únicamente de una determinada realidad que se pretende sea descrita. $\mathrm{La}$ caracterización a la que hemos intentado aproximarnos es bastante compleja y es posible advertir variados matices. Por una parte implica un cierto sistema clasificatorio, una determinada mirada que por una parte organiza los distintos grupos puneños entre "indios de guerra", indios "medio de paz medio de guerra" y grupos "pacificados", otorgándoles características culturales y sociales predeterminadas a cada uno de ellos de acuerdo a su respectiva posición en el eje "naturaleza-sociedad" y que, por otra, expresa, aun al interior de una discursividad burocrática, una determinada concepción de los espacios sociales y del papel del pacificador, como figura principal de tránsito entre esos dos espacios.

Uno de los problemas que surgen de esta aproximación es el de una complicada relación entre dos formas diferentes de estructurar lo dicho: lo "real" o lo "verídico" y lo "verosímil". Para que un relato parezca verídico tiene que ser creíble, debe cumplir con una exigencia de verosimilitud, y aquí surge, de inmediato, la interrogante sobre las condiciones sociales de existencia de ese relato y las relaciones que éste guarde con la "realidad" descrita. No sé si se me entiende bien, ya no se trata tan sólo de que un relato cualquiera resulta de una selección anticipada de los hechos a narrar (lo que una sociedad privilegia por considerar importante 
o relevante) y de una eliminación de todo aquello considerado secundario o irrelevante (Finlay 1977), sino de la introducción de determinadas categorías descriptivas que son intercaladas en el relato y que lo hacen creíble, como una exigencia que se antepone a la veracidad, pero que no tiene relación con la realidad de lo narrado, sino con el sistema de representaciones de una sociedad. El enunciado que revisamos me parece que expresa constantemente esta situación que, por ahora, sólo podemos entrever en sus aspectos más generales pero no por eso menos inquietantes.

Si los textos poseen un volumen y éste es el resultado de un diálogo intertextual, entonces la posibilidad metodológica del abordaje heterogéneo podría ser correcta, ya que una misma discursividad -o partes de ella- pudieran estar cruzando los tipos documentales o hacerse presentes en el relato escrito. A lo largo de este análisis, sin embargo, los documentos han sufrido un desplazamiento, el relato lineal que se soñó cruzar para mirar más allá, se ha revelado como un cruce de caminos que confluyen y se separan, se superponen y se oponen; los "temas" que se podrían buscar ya no parecen tampoco los mismos, o al menos habría que replantearlos. Si la heterogeneidad aún nos parece correcta, es únicamente a condición de aceptar que el abordaje del análisis textual pone al documento y a los discursos que contiene en un plano diferente, que aún deberemos perfilar, que requiere todavía de nuevos trabajos.
En este sentido la pregunta inicial acerca de la posibilidad de que estos datos puedan ser usados libremente, al margen del tipo de documentos del cual se extraigan, debe ser replanteada. Del análisis surge el valor de una categoría metodológica intermedia entre el tipo de documento y el dato, que es necesario tener en cuenta: el enunciado. Creo que los datos pueden ser utilizados libremente pero a condición de hacerlo al interior del espacio marcado por cada enunciado, puesto que éste parece ser la unidad que les otorga sentido y organización. En esta perspectiva y sin negar la existencia de ciertas series documentales (cuyas condiciones de producción y existencia no exploramos aquí), me parece que la introducción de la categoría enunciado hace necesario intentar pensarlas en un sentido horizontal, cuestión que desconocíamos al inicio de este trabajo.

Santiago, septiembre de 1992.

Agradecimientos Este trabajo es resultado del proyecto 90-525 de CONICYT. En muchos sentidos, éste es un trabajo colectivo, resultado de largas y apasionadas discusiones entre todos los integrantes del Taller de Investigación del Museo Chileno de Arte Precolombino y de mis colegas del equipo de investigación de etnohistoria, de los proyectos de tesis y también de vida de algunos de ellos. A Francisco Gallardo y Viviana Manríquez, que leyeron, criticaron, comentaron y aportaron a los borradores iniciales de este trabajo, les debo un agradecimiento especial.

\section{REFERENCIAS CITADAS}

\section{Documentos inéditos}

Archivo General de Indias

AGI Patronato $188 \mathrm{n}^{\circ} 1$

AGI Patronato $188 \mathrm{n}^{\circ} 4$

AGI Charcas 80

AGI Patronato 29 ramo 39 año 1587

AGI Patronato 137 doc. 1 ramo 11

AGI Patronato 95-B ramo 6

Biblioteca Nacional de Buenos Aires

(Col. Gaspar García Viñas)

BNBA Col. GGV, doc. 1400

BNBA Col. GGV, doc. 1481

BNBA Col. GGV, doc. 1234

Archivo Nacional de Bolivia

ANBC 1591. VII.19 n 417
Impresos

ALDUNATE, C. y V. CASTRO, 1981. Las chullpa de Toconce y su relación con el poblamiento altiplánico en el Loa Superior, Período Tardío, Ediciones Kultrún, Santiago.

ALDUNATE, C., J. BERENGUER y V. CASTRO, 1982. La función de las chullpa en Likán. Actas del $7^{\circ}$ Congreso de Arqueología Chilena. Ediciones Kultrún, Santiago.

ALDUNATE, C., J. BERENGUER, V. CASTRO, L. CORNEJO, J. L. MARTINEZ y C. SINCLAIRE, 1986. Cronología y asentamiento en la región del Loa Superior. Universidad de Chile, Departamento de Investigación y Bibliotecas, Santiago.

ARANIBAR, C., 1963. Algunos problemas heurísticos en las crónicas de los siglos XVI-XVII. Nueva Crónica 1: 104-135.

BARNADAS, J. M., 1973. Charcas. Orígenes históricos de una sociedad colonial. CIPCA, La Paz. 
BARTHES, R., 1990. La aventura semiológica. Paidós Comunicación, Barcelona.

BIBAR, G. DE, 1979 [1558]. Crónica y relación copiosa y verdadera de los Reinos de Chile. Bibliotheca Ibero-Americana, Collquium Verlag, Berlín.

BOUYSSE CASSAGNE, T., 1992. Le lac Titicaca. Historie perdue d'une mer intérieure. Boletín del Instituto Francés de Estudios Andinos 21 (1): 89-159.

CALAME, C., 1990. Du fíguratif au thématique. aspects narratifs et interprétatifs de la description en anthropologie de la Gréce ancienne. En Le discours anthropologique, J. M. Adam et al. (Eds.), pp. 111-132. Méridiens Klinck-sieck, París.

CASARES, J., 1989. Diccionario ideológico de la lengua española. Editorial Gustavo Gili, Barcelona.

FERNANDEZ DE OVIEDO, G., 1945 [1549]. Historia general y natural de las Indias. Editorial Guáranla, Asunción.

FINLAV, M. I., 1977. Mito, memoria e historia. En Uso y abuso de la Historia, M. Finlay (Ed.), pp. 11-44. Editorial Grijalbo, Barcelona.

FOUCAULT, M., 1989 [1968]. Las palabras y las cosas. Siglo XXI, México D. F.

GENTILE, M., 1988. Evidencias e hipótesis sobre los atacamas en la Puna de Jujuy y Quebrada de Humahuaca. Journal de la Société des Americanistes LXXIV: 87-103.

GINSBURG, G., 1992. El inquisidor como antropólogo. Mapocho 31: $103-112$

GREIMAS, A. J., 1987. Semántica estructural. Editorial Gredos, Madrid.

GREIMAS, A. J. y J. COURTES, 1979. Sémiotique. Dictionaire raisonné de la Théorie du Langage. Hachette, París.

HAROMAN, M., 1988. Jaqi Aru. La lengua humana. En Raíces del mundo. El mundo aymara, X. Albó (Ed.), pp. 155-216. Alianza Editorial, Madrid.

HIDALGO, J., 1978. Incidencias de los patrones de poblamiento en el cálculo de la población del Partido de Atacama desde 1752 a 1804. Las revisitas inéditas de 1787-1792 y 1804. Estudios Atacameños 6: 53-111.

HIDALGO, J. y G. FOCACCI, 1986. Multietnicidad en Arica, siglo XVI Evidencias etnohistóricas y arqueológicas. Chungara 16-17: 137-147.

HYSLOP, J., 1979. El área lupaca bajo el dominio incaico, un reconocimiento arqueológico. Histórica 3 (1): 53-79.

KRAPOVICKAS, P., 1978. Los indios de la Puna en el siglo XVI. Relaciones Nueva Serie XII: 71-93.

1983. Las poblaciones indígenas históricas del sector oriental de la Puna (un intento de correlación entre la información arqueológica y la etnográfica). Relaciones Nueva Serie XV: 7-24.
LEVILLIER, R., 1920-27. Gobernantes del Perú. Cartas y papeles, siglo XVI. Imprenta de Juan Pueyo, Madrid.

LIZARRAGA, FRAY R. DE, 1987 [1607]. Descripción del Perú, Tucumán, río de la Plata y Chile. Historia 16, Madrid.

LORANDI, A. M., 1977. Arqueología y etnohistoria. Hacia una visión totalizadora del mundo andino. Obra del Centenario del Museo de La Plata II: 27-50.

1988. La resistencia y rebeliones de los diaguita-calchaquí en los siglos XVI y XVII. Cuadernos de Historia 8: 99-122.

- 1988Ms. Notas sobre la percepción incaica de Chile y Tucumán. Ponencia presentada en el XI Congreso de Arqueología Chilena, Santiago.

1991Ms. La utopía andina en las fronteras del imperio. Ponencia presentada en el II Congreso Internacional de Etnohistoria, Coroico.

LORANDI, A. M. y R. BOIXADOS, 1987-88. Etnohistoria de los valles calchaquíes en los siglos XVI y XVII. Runa XVII-XVIII: 263-419.

LORANDI, A. M. y C. BUNSTER, 1987-88. Reflexiones sobre las categorías semánticas en las fuentes del Tucumán colonial. Los valles calchaquíes. Runa XVII-XVIII: 221-262.

LOZANO MACHUCA, J., 1885 [1581]. Carta del Factor de Potosí... al virrey del Perú, en donde se describe la provincia de los Lipes. Relaciones Geográficas de Indias, Perú, vol. 2, Apéndice III: XXI-XXVIII, Madrid.

MARTINEZ, J. L., 1985. Información sobre el comercio de pescado entre Cobija y Potosí, hecha por el Corregidor de Atacama, don Juan de Segura (19 de julio de 1591). Cuadernos de Historia 5: 161-171.

MARTINEZ, J. L, A. M. FARIAS, C. ODONE y P. BLAZQUES, 1988. Dispersión y movilidad en Atacama colonial. Encuentro de etnohistoriadores. Serie Nuevo Mundo. Cinco siglos 1: 53-69.

1990. Interetnicidad y complementariedad en el Altiplano Meridional. El caso atacameño. Andes 1: 11-30.

1991. Acerca de las etnicidades en la Puna árida en el siglo XVI. Actas del II Congreso Internacional de Etnohistoria, vol. 1. Hisbol, La Paz.

MEDINA, J. T., 1896-1900. Colección de documentos inéditos para la Historia de Chile. Imprenta Elzeviriana, Santiago.

MONTANER y SIMON (Eds.), 1912. Diccionario enciclopédico hispano-americano. Montaner y Simón Editores Sociedad Internacional, Barcelona.

MURRA, J., 1975. Formaciones económicas y políticas del mundo andino. Instituto de Estudios Peruanos, Lima.

1979. Los olleros del Inca. Hacia una historia y arqueología del Qollasuyu. En Historia: Problema y promesa. Homenaje a Jorge Basadre, F. Miro Quezada, F. Pease y D. Sobrevilla (Eds.). Universidad Católica del Perú, Lima. 
OÑA, P. DE, Arauco domado, Editorial Universitaria, Santiago.

PEASE F., Ms. Etnohistoria andina: Problema de fuentes y metodología. Universidad Católica del Perú, Lima.

1977 (Ed.). Collaguas I. Universidad Católica del Perú, Fondo Editorial, Lima.

_ 1978a. Del Tawantinsuyo a la historia del Perú. Instituto de Estudios Peruanos, Lima.

1978b. Las visitas como testimonio andino. En Historia: Problema y promesa. Homenaje a Jorge Basadre, F. Miro Quesada, F. Pease y D. Sobrevilla (Eds.). Universidad Católica del Perú, Lima.

_ 1991a. Los incas. Universidad Católica del Perú, Lima.

— 1991b. Los últimos incas del Cuzco. Alianza Editorial, Madrid.

REAL ACADEMIA ESPAÑOLA, 1970. Diccionario de la lengua española. Espasa-Calpe, Madrid.

ROSTWOROWSKI, M., 1977. Etnia y sociedad. Costa peruana prehispánica. Instituto de Estudios Peruanos, Lima.

- 1981. La voz parcialidad en su contexto en los siglos XVI y XVII. En Etnohistoria y antropología andina, A. Castelli, M. Koth y M. Mould (Eds.), pp. 35-45. Museo Nacional de Historia, Lima.

1988. Historia del Tawantinsuyo. Instituto de Estudios Peruanos, Lima.

SAIGNES, T., 1980. Una provincia andina a comienzos del siglo XVII. Pacajes según una relación inédita. Historiografía y bibliografía americanistas XXIV: 1-21.
- 1986. En busca del poblamiento étnico en los Andes bolivianos (siglos XV y XVI). Avances de Investigación 3. Museo de Etnografía y Folklore, La Paz.

SCHAPOSCHNIK, A., 1991Ms. ¿Cómo trabajamos con fuentes de escasos datos? Reflexión metodológica. Ponencia presentada al II Congreso Internacional de Etnohistoria, Coroico.

SILVA LEZAETA, L., 1953. EI conquistador Francisco de Aguirre. Fondo Histórico y Bibliográfico J. T. Medina, Santiago.

TELLEZ, E., 1984. La guerra atacameña en el siglo XVI: Implicancias y trascendencia de un proceso de resistencia indígena en el despoblado de Atacama. Estudios Atacameños 7: 399-421.

TELLEZ, E. y O. SILVA, 1989. Atacama en el siglo XVI. La conquista hispana en la periferia de los Andes Meridionales. Cuadernos de Historia 9: 45-69.

URTON, G., 1989. La historia de un mito. Paqariqtambo y el origen de los incas. Revista Andina 13: 129-216.

WACHTEL, N., 1976. Los vencidos. Los indios del Perú frente a la conquista española (1530-1570). Alianza Editorial, Madrid.

WEDIN, A., 1966. El concepto de lo incaico y las fuentes. Studia Histórica Gothoburgensia VII, Upsala.

ZUIDEMA, T., 1973. Una interpretación alternativa de la historia incaica. La segunda representación. En Ideología mesiánica en el mundo andino, J. Ossio, (Ed.), pp. 2-33. Ed. de Ignacio Prado, Lima.

- 1977. Mito e historia en el antiguo Perú. Allpanchis Phuturinga X: 15-52.

1990. Inca civilization in Cuzco. University of Texas Press, Austin. 